\title{
Effectiveness of a Mindfulness-Based Intervention for Athletes
}

\author{
Darko Jekauc, Christoph Kittler, Marcel Schlagheck \\ Department for Sport and Exercise Psychology, Humboldt University of Berlin, Berlin, Germany \\ Email: darko.jekauc@hu-berlin.de
}

How to cite this paper: Jekauc, D., Kittler, C., \& Schlagheck, M. (2017). Effectiveness of a Mindfulness-Based Intervention for Athletes. Psychology, 8, 1-13.

http://dx.doi.org/10.4236/psych.2017.81001

Received: November 30, 2016

Accepted: December 26, 2016

Published: December 30, 2016

Copyright (C) 2017 by authors and Scientific Research Publishing Inc. This work is licensed under the Creative Commons Attribution International License (CC BY 4.0).

http://creativecommons.org/licenses/by/4.0/

\begin{abstract}
Recently, several top athletes, as well as coaches, have revealed that mindfulness can be regarded as a type of psychological training to optimize performance. Indeed, results of studies in clinical psychology, as well as neuroscience, suggest that mindfulness might be an effective strategy to promote concentration, emotion regulation and state of flow. However, the empirical evidence in the context of sport is rather sparse. The aim of this study was to examine the effectiveness of a mindfulness-based intervention in athletes. In a randomized controlled trial with 22 participants in the experimental and 24 participants in the control group, the effectiveness of the Berlin Mindfulness-based Training for Athletes (BATL) was tested and compared to a classical sport psychological intervention. The results of an analysis of covariance with repeated measures indicate that the intervention group significantly improved mindfulness as a trait compared to the control group. It can be concluded that BATL is an effective strategy to increase mindfulness in athletes. However, further studies are needed to evaluate the effectiveness of this intervention in improving performance and to be able to examine its effect mechanisms.
\end{abstract}

\section{Keywords}

Mindfulness, Intervention, Athletes, Sport Psychology, Randomized Trial

\section{Introduction}

The idea that mindfulness can help athletes to improve their mental fitness and thus their performance is not new. Indeed, several top athletes as well as coaches have recently revealed that mindfulness can be regarded as a type of psychological training to optimize performance. One prominent example is Phil Jackson who is one of the most successful basketball coaches in the history of the NBA. In the early nineties, he revealed that he regularly practiced meditation and other 
forms of mindfulness to improve the performance of his team (Jackson \& Delehanty, 1996). Despite the public support of these commitments, mindfulness has long been perceived in the western world as an unscientific religious practice or esotericism. However, inspired by eastern philosophy some research in psychology and neurosciences has helped to develop several therapeutic interventions (Baer, 2003). The analyses of their effectiveness has provided evidence that mindfulness-based interventions were effective in reducing anxiety (Hofmann, Sawyer, Witt, \& Oh, 2010) and symptoms of stress (Chiesa \& Serretti, 2009) as well as improving well-being (Keng, Smoski, \& Robins, 2011) and cognitive ability (Chiesa, Calati, \& Serretti, 2011). As cognitive ability (e.g. concentration) and emotion regulation strategies are prerequisites for peak performances in competitive sport it is apparent that mindfulness training could serve as a mental practice technique in competitive sport.

Mindfulness has been defined as "the awareness that emerges through paying attention on purpose, in the present moment, and non-judgmentally to the unfolding of experience moment by moment" (Kabat-Zinn, 1994: p. 4). The aim is to stay aware of the present moment without judging one's own thoughts, emotions and perceptions. According to Bishop et al. (2004) mindfulness comprises two components: Self-regulation of attention and orientation to experience. The first component self-regulation of attention means to observe and to attend to the changing aspects of thoughts, feelings, and sensations from moment to moment. This increased attention leads to a feeling of alertness to what is happening in the here-and-now. To achieve this feeling, sustained attention is required which can be regarded as a trainable skill. The second component refers to the orientation to experience that is characterized by curiosity, openness and acceptance. "Rather than observing experience through the filter of our beliefs, assumptions, expectations, and desires, mindfulness involves a direct observation of various objects as if for the first time" (Bishop et al., 2004: p. 33).

Classical sport psychological techniques are based on the assumption that the ability to control one's own psychological and bodily states is a prerequisite for optimal performance in sport (Hardy, Jones, \& Gould, 1996). On the contrary, mindfulness-based techniques prescribe to accept and observe the present states without judging them. By doing this, athletes distance themself from their feelings, thoughts and perceptions by taking the perspective of an external observer. In this state, the person realizes which feelings and thoughts are occurring without identifying with them. This external observer perspective prevents the athlete from getting overrun by his or her own feelings and thoughts and opens up the opportunity to consciously decide whether to follow the thoughts or to focus on something else. Using this technique, the athlete gains emotional stability and learns to maintain focus on what is occurring in the moment.

Three possible mechanisms of how mindfulness influences performance in sport have been discussed in the literature (see Figure 1). Firstly, it was speculated that mindfulness facilitates the development of flow, a state of optimal functioning which is associated with peak performances (Csikszentmihalyi, 1990). 


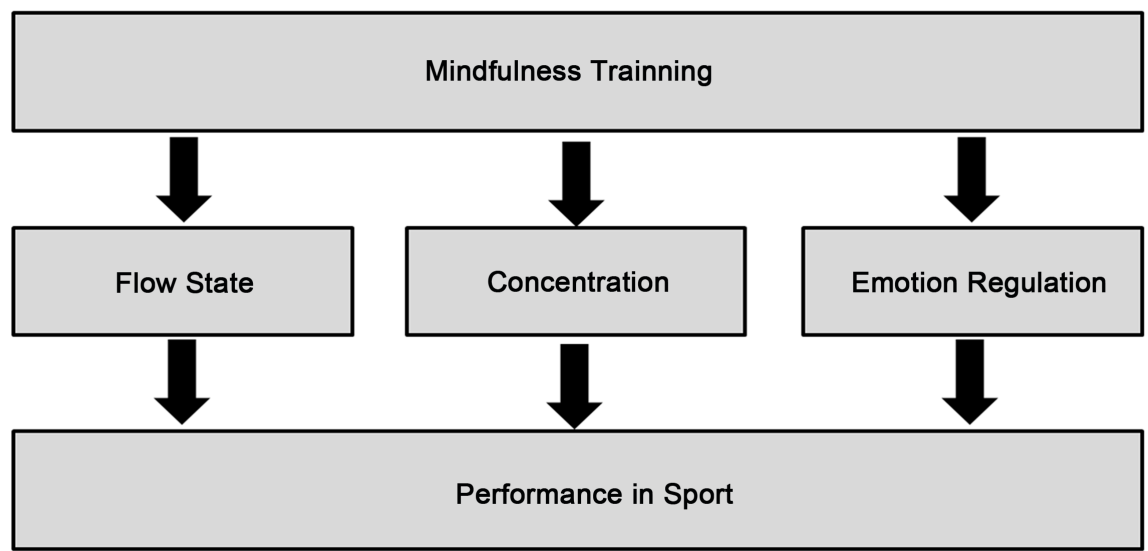

Figure 1. Mechanisms of how mindfulness influences performance in sport.

Secondly, it is assumed that training mindfulness positively affects attention especially in the regulation and maintenance of attention in task-related aspects of sports. Thirdly, it is supposed that the training of mindfulness positively influences the development of emotion regulation strategies (Gross \& John, 2003).

The state of flow is often described as the state of optimal performance (Csikszentmihalyi, 1990). Typically, this state emerges when a balance between challenges of the situation and the abilities of the person exists. The athletes so involved with the task that all other things are extraneous. This state is regarded to be optimal for success as body and mind are synchronized, negative thoughts vanish and space for enjoyment in the task emerges (Jackson \& Csikszentmihalyi, 1999).

Gardner and Moore (2004) assume that flow and mindfulness have a substantial conceptual overlap. Both concepts emphasize the mental task of being present in the moment and the self-forgotten concentration. Empirical studies seem to support this thesis. Substantial and significant correlations were found between both constructs in elite French swimmers (Bernier, Thienot, Cordon, \& Fournier, 2009), archers and golfers (Kaufman, Glass, \& Arnkoff, 2009), rowers (Pineau, Glass, Kaufman, \& Bernal, 2014) as well as runners (Pineau, 2013). Additionally, it was shown that after completing a mindfulness program, the level of perceived flow increased (Aherne, Moran, \& Longsdale, 2011; Kaufman et al., 2009). The results of these studies indicate that mindfulness training facilitates the perception of flow, which is associated with increased sport performance. Doing sport in a mindful manner could foster the development of flow during competition periods. However, the methodological quality of the studies (e.g. small sample sizes or lack of a control group) substantially impairs the validity of the findings.

Concentration and attention seem to be prerequisites for peak performance in sport (Moran, 1996). As mentioned above, the regulation of attention is an essential characteristic of mindfulness. Most practices in mindfulness focus on drawing attention on a particular sensation such as one's own breath. Empirical studies seem to support the thesis that mindfulness training enhances attention (see for a review Chiesa et al., 2011). Empirical evidence outside the sporting 
context suggests that mindfulness training improves selective attention (Chan \& Woollacott, 2007; Jensen, Vangkilde, Frokjaer, \& Hasselbalch, 2012; van den Hurk, Giommi, Gielen, Speckens, \& Barendregt, 2010), sustained attention (Chambers, Lo, \& Allen, 2008; Valentine \& Sweet, 1999), orienting attention (Jensen et al., 2012; Moore \& Malinowski, 2009) as well as attention flexibility (Hodgins \& Adair, 2010). Furthermore, studies in neuroscience show that regular mindfulness meditation leads to structural changes in brain regions which are associated with attention regulation such as the anterior cingulate cortex (Cahn \& Polich, 2006). According to Moore, improvement of one's attention through mindfulness training is an essential mechanism of mindfulness in order to improve performance in sport. However, empirical studies in sport context are lacking entirely so as to be able to examine this mechanism. Alone, statements of athletes in case studies suggest that mindfulness training leads to improvement in attention and concentration skills (e.g. Schwanhausser, 2009).

Emotion regulation seems to be an important skill to reach optimal performance in sport (Robazza, Pellizzari, \& Hanin, 2004). Several studies support the thesis that mindfulness training can influence emotion regulation. For example, participants of mindfulness training programs have reported, subsequently, a decrease in difficulty in regulating their own emotions (Robins, Keng, Ekblad, \& Brantley, 2012), a reduction of intensity and frequency of negative feelings (Chambers et al., 2008; Zeidan, Johnson, Gordon, \& Goolkasian, 2010) as well as an increase in positive feelings (Geschwind, Peeters, Drukker, van Os, \& Wichers, 2011; Jain et al., 2007; Tang et al., 2007). Furthermore, it has been shown that mindfulness training can reduce the detrimental effect of emotional interference on performance in cognitive tasks (Ortner, Kilner, \& Zelazo, 2007). It seems that people who regularly practice mindfulness develop a better ability to be able to blank out distracting emotional stimuli and to fully concentrate on the relevant task. Evidence of the effect on mindfulness, in a sporting context, is substantially weaker. Mindfulness was found to negatively correlate with competition anxiety (Thompson, Kaufman, De Petrillo, Glass, \& Arnkoff, 2011) and positively with competition optimism (Kaufman et al., 2009). Furthermore, it has been shown that the training of mindfulness can decrease competition anxiety (De Petrillo, Kaufman, Glass, \& Arnkoff, 2009).

Currently, two mindfulness-based programs for athletes exist: MindfulnessAcceptance-Commitment Approach (MAC; Gardner \& Moore, 2004) and Mindful Sports Performance Enhancement (MSPE; Kaufman et al., 2009). MAC is a program consisting of seven modules (sessions) which was validated in several case studies (Gardner \& Moore, 2004; Lutkenhouse, 2007; Schwanhausser, 2009) as well as in intervention studies (Gardner \& Moore, 2007; Hasker, 2010; Ivarsson, Johnson, Andersen, Fallby, \& Altemyr, 2015; Wolanin, 2004). The results of these studies suggest that MAC might have positive effects on attention and performance whereas the methodological quality of these studies is rather low due to low sample sizes, lack of randomization or an invalid measurement of performance. MSPE is a 4-week mindfulness program which was specifically 
developed for athletes. The validation studies suggest that the program significantly increases flow experience and self-confidence of athletes (Kaufman et al., 2009) as well as decreasing competition anxiety (De Petrillo et al., 2009). However, nothing is known about how effective these mindfulness programs are in comparison to established sport psychological programs.

The huge amount of empirical evidence suggests that mindfulness-based programs in sport could have positive effects on psychological correlates of performance such as concentration, emotion regulation and flow. However, this empirical evidence is based on studies either beyond the sporting context or within the sporting context but with rather low methodological quality. Therefore, randomized controlled trials are needed to show efficacy of the mindfulness programs. Moreover, effect mechanisms showing how mindfulness training influences performance in different sporting disciplines is not fully understood. Theory-driven research is needed to establish the link between mindfulness training and improvement of performance. Furthermore, it would be useful to evaluate its efficacy compared to other established sport psychological programs in order to determine its relative utility.

The aim of this study is to evaluate the efficacy of a mindfulness-based program and compare it to an established sport psychological program. This mindfulness-based program was developed and applied to German speaking athletes. The hypothesis of this study is that this program has an effect on mindfulness and that it is more effective than a classical sport psychological program.

\section{Methods}

\subsection{Participants}

72 students in sport science of Humboldt University Berlin were recruited for this study using simple random sampling method. Due to various reasons, 26 participants dropped out or were excluded from analyses as a result of missing data. Finally, 46 participants ( 15 men and 31 women) were included in the analysis of which 22 participants were randomly assigned to the experimental group and 24 participants to the control group. The mean age of the participants was 23.4 years old $(\mathrm{SD}=4.1$ years).

\subsection{Procedure}

In order to take part in this study, bachelor students of sport science subscribed to a practical course in sport psychology and three different dates were offered for it. In the first week of the study, students were randomly assigned either to an experimental or to a control group. The courses for experimental and control group took part at the same time and had the same duration. The dependent variable was measured on three occasions: In the first, fourth and in the final session. Each session had duration of 90 minutes and the first 60 minutes were used to practice either mindfulness or other sport psychological techniques. The remaining 30 minutes of each session was used to answer questions concerning 
lectures in sport psychology.

In the experimental group, the students participated in the BATL (Berliner Achtsamkeitstrainigzur Leistungsoptimierung/Berlin Mindfulness Training for Performance Enhancement) which has duration of 8 weeks. In each session, a combination of psycho-education about mindfulness and its effects as well as mindfulness exercises were conducted. Orienting on MAC, different exercises such as centering, breath meditation, body scan and mindfulness meditation were used. In the first two sessions, most of the time was spent on psycho-education. During the progression of the course, the amount of time spent in psycho-education decreased and mindfulness exercises increased.

In the control group, the students learned about sport psychological topics and applied different exercises consistent with these topics. Topics for the control group were motivation, stress, fear, teambuilding, visualization, self-confidence, goal setting and concentration. The sport psychological techniques taught in the control group based on the contents described by Weinberg and Gould (2014).

\subsection{Measurement}

The dependent variable in this study was mindfulness. The German version of the Mindful Attention Awareness Scale (MAAS; Michalak, Heidenreich, Ströhle, \& Nachtigall, 2008) was used to asses if the level of mindfulness changed throughout the intervention. This version is a translated version of the MAAS by Brown and Ryan (2003). The MAAS consists of 15 questions with a 6-point Likert Scale $(1=$ almost always, $6=$ almost never $)$. The questionnaire has a onedimensional structure. The German version has an internal consistency of $a$ $=0.83$.

\subsection{Statistical Analyses}

The statistical analyses were conducted using IBM SPSS Statistics 23. The first step was to control and to correct for item-nonresponse. In the second step, descriptive statistics were calculated for both groups on all three measurement occasions. In the third step, analysis of covariance (ANCOVA) with repeated measurements was conducted in which age and sex were covariates. Mauchly's sphericity test (Mauchly W $=0.753$; Epsilon $=0.90 ; \chi^{2}=12.2 ; \mathrm{df}=2 ; p<0.01$ ) indicated that sphericity assumption was violated. According to Girden (1992), the Huynh-Feldt correction for ANCOVA should be applied when epsilon is higher than 0.75 .

\section{Results}

\subsection{Descriptive Results}

Descriptive statistics are presented in Table 1. The mean of the intervention group was 3.95 before the start of the intervention and 4.15 at the end of the intervention meaning that there was an increase in MAAS during the progress of the intervention. The mean of the control group was 4.12 before the intervention 
Table 1. Descriptive statistics.

\begin{tabular}{ccccccc}
\hline & \multicolumn{3}{c}{ Intervention Group } & \multicolumn{3}{c}{ Control Group } \\
\cline { 2 - 7 } & $n$ & $M$ & $S D$ & $n$ & $M$ & $S D$ \\
\hline $\mathrm{t} 1$ & 22 & 3.95 & 0.70 & 24 & 4.12 & 0.63 \\
$\mathrm{t} 2$ & 22 & 4.13 & 0.66 & 24 & 3.97 & 0.70 \\
$\mathrm{t} 3$ & 22 & 4.15 & 0.67 & 24 & 3.83 & 0.79 \\
\hline
\end{tabular}

Note: $n=$ number of participants in the group; $M=$ mean; $S D=$ standard deviation.

started and 3.83 at the end of the intervention. The progression of the mean over time indicates that MAAS decreased from the first to the third measurement occasion.

\subsection{Inference Statistics}

The results of the analysis of covariance with repeated measurements show that time did not have a significant effect (see Table 2). This means that the overall mean does not significantly change over time. The two-way interactions between time and age as well as between time and sex is also not significant meaning that age and sex do not significantly influence development of MAAS over time. However, the two-way interaction between time and group is significant, showing that the development of MAAS of both groups significantly differs. In the intervention group, the mean of MAAS increases over time whereas the mean of the control group decreases during the intervention (see Figure 2). Eta-square is 0.13 indicating that the interaction between time and group explains about $13 \%$ of the within-person variance. Three-way interaction between time, group and sex is also not significant.

\section{Discussion}

A mindfulness-based program in the German language was developed for athletes. This study was a first step to be able to evaluate the efficacy of this program in comparison to an established sport psychology program. The hypothesis of this study was that mindfulness-based training is more effective in influencing the mindfulness of athletes than a classical sport psychological program.

In order to test this hypothesis a randomized control trial with 22 participants in the mindfulness group and 24 participants in the sport psychology group was conducted. The results of this study suggest that mindfulness training had, in comparison to a classical sport psychology program, a significant effect. Participants of the mindfulness group increased their MAAS score whereas the participants in the control group decreased their MAAS score. This decrease in MAAS score of the control group can be explained by the level of stress experienced by the students during the semester which continually increases because the pressure mounts due to the approaching deadlines for written homework and examinations. The students are faced with managing a growing number of tasks as 


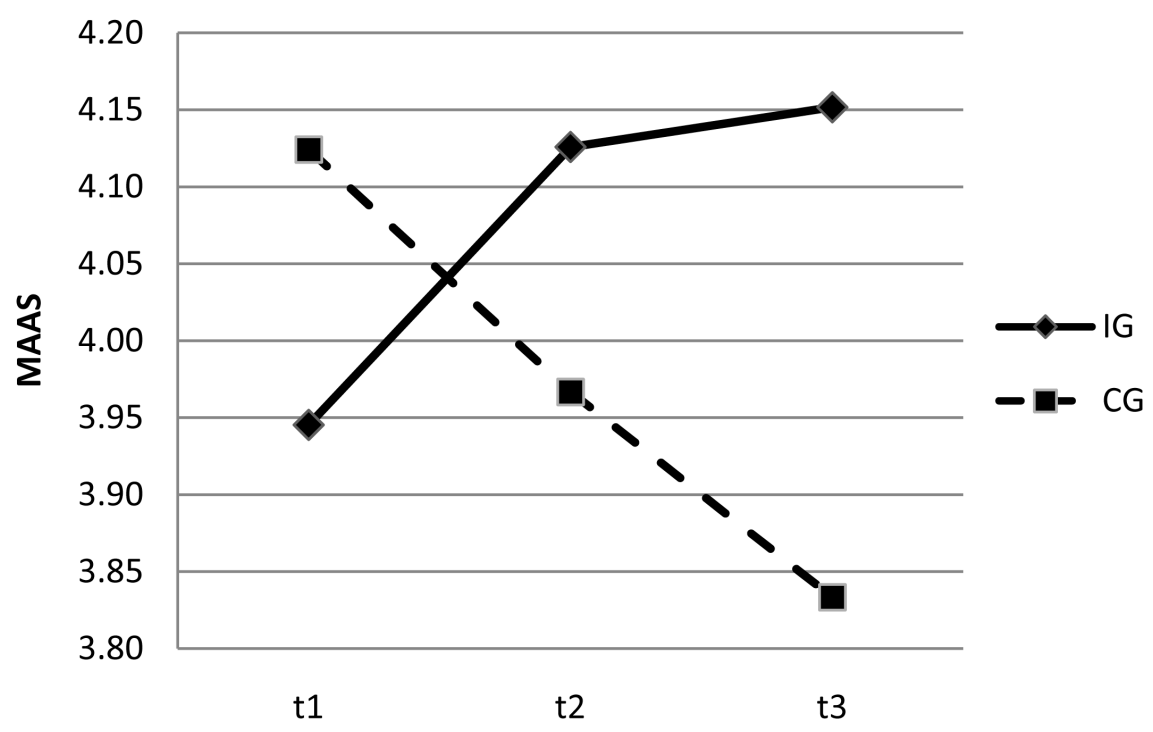

Figure 2. Development of the means $(\mathrm{IG}=$ intervention group; $\mathrm{CG}=$ control group).

Table 2. Analysis of covariance with repeated measurements.

\begin{tabular}{ccccccc}
\hline & $S S$ & $d f$ & $M S S$ & $F$ & $p$ & $\eta^{2}$ \\
\hline Time & 0.52 & 1.79 & 0.29 & 2.15 & 0.13 & 0.05 \\
Time * Age & 0.59 & 1.79 & 0.33 & 2.41 & 0.10 & 0.06 \\
Time * Group & 1.50 & 1.79 & 0.84 & 6.19 & 0.00 & 0.13 \\
Time * Sex & 0.21 & 1.79 & 0.11 & 0.85 & 0.42 & 0.02 \\
Time* Group ${ }^{*}$ Sex & 0.29 & 1.79 & 0.16 & 1.21 & 0.30 & 0.03 \\
Error & 9.93 & 73.57 & 0.14 & & &
\end{tabular}

Note: $S S=$ sum of squares; $d f=$ degrees of freedom; $M S S=$ mean sum of squares; $p=$ probability value.

the end of semester approaches which results in a higher general level of stress. A huge body of evidence suggests that the training of mindfulness reduces the perception of stress (Goyal et al., 2014). However, it can be assumed that this effect is reciprocal so that stress level can increase the perception of mindfulness. Although we did not explicitly test this hypothesis, we assume in this study that mindfulness training acted as a stress buffer. However, further studies are needed to evaluate this hypothesis. Noticeably, neither age nor sex had a significant effect on mindfulness. Hence, it can be assumed that the effects of mindfulness training are independent of age and sex.

The results of this study suggest that BATL is an effective program to increase mindfulness as a trait. However, it is unknown whether this program can influence performance in sport, emotion regulation strategies, concentration or flow state. This study represents a first step to establish the role of mindfulness training as a tool for improve of performance in sport. Further studies are needed to test the mechanisms in which way mindfulness influences sport performance.

This study has several strengths and limitations. A major strength of this study is that it provides a randomized control trial, which enables one to draw a 
strong conclusion about the efficacy of the program. Furthermore, this program was shown to be effective in comparison to a classical sports psychology program. To our knowledge this efficacy had not been yet established. The limitations of this study are that the sample size is relatively small but still large enough to show the efficacy of the program. Furthermore, sport performance was not measured to examine its efficacy and effect mechanisms. Finally, it is unknown how sustainable these effects are. Therefore, further intervention studies are needed to examine the mechanisms and sustainability of the effects.

\section{Conclusion}

The results of this study lead to the conclusion that the Berlin Mindfulnessbased Training for athletes (BATL) is effective in increasing the trait of mindfulness. In this regard, BATL is more effective than a classical sport psychology programs for athletes. This program seems to work as a stress buffer. However, further intervention studies with mediation analyses are needed to examine whether BATL has an influence on performance as well as its effect mechanisms and sustainability.

\section{References}

Aherne, C., Moran, A. P., \& Longsdale, C. (2011). The Effect of Mindfulness Training on Athletes' Flow: An Initial Investigation. The Sport Psychologist, 25, 177-189. https://doi.org/10.1123/tsp.25.2.177

Baer, R. A. (2003). Mindfulness Training as a Clinical Intervention: A Conceptual and Empirical Review. Clinical Psychology: Science and Practice, 10, 125-143. https://doi.org/10.1093/clipsy.bpg015

Bernier, M., Thienot, E., Cordon, R., \& Fournier, J. F. (2009). Mindfulness and Acceptance Approaches in Sport Performance. Journal of Clinical Sport Psychology, 25, 320-333. https://doi.org/10.1123/jcsp.3.4.320

Bishop, S. R., Lau, M., Shapiro, S., Carlson, L., Anderson, N. D., Carmody, J. et al. (2004). Mindfulness: A Proposed Operational Definition. Clinical Psychology: Science and Practice, 11, 230-241. https://doi.org/10.1093/clipsy.bph077

Brown, K. W., \& Ryan, R. M. (2003). The Benefits of Being Present: Mindfulness and Its Role in Psychological Well-Being. Journal of Personality and Social Psychology, 84, 822-848. https://doi.org/10.1037/0022-3514.84.4.822

Cahn, B. R., \& Polich, J. (2006). Meditation States and Traits: EEG, ERP, and Neuroimaging Studies. Psychological Bulletin, 132, 180-211. https://doi.org/10.1037/0033-2909.132.2.180

Chambers, R., Lo, B. C. Y., \& Allen, N. B. (2008). The Impact of Intensive Mindfulness Training on Attentional Control, Cognitive Style, and Affect. Cognitive Therapy and Research, 32, 303-322. https://doi.org/10.1007/s10608-007-9119-0

Chan, D., \& Woollacott, M. (2007). Effects of Level of Meditation Experience on Attentional Focus: Is the Efficiency of Executive or Orientation Networks Improved? The Journal of Alternative and Complementary Medicine, 13, 651-658. https://doi.org/10.1089/acm.2007.7022

Chiesa, A., \& Serretti, A. (2009). Mindfulness-Based Stress Reduction for Stress Management in Healthy People: A Review and Meta-Analysis. The Journal of Alternative and Complementary Medicine, 15, 593-600. https://doi.org/10.1089/acm.2008.0495 
Chiesa, A., Calati, R., \& Serretti, A. (2011). Does Mindfulness Training Improve Cognitive Abilities? A Systematic Review of Neuropsychological Findings. Clinical Psychology Review, 31, 449-464. https://doi.org/10.1016/j.cpr.2010.11.003

Csikszentmihalyi, M. (1990). Flow: The Psychology of Optimal Performance. New York: Cambridge University Press.

De Petrillo, L. A., Kaufman, K. A., Glass, C. R., \& Arnkoff, D. B. (2009). Mindfulness for Long-Distance Runners: An Open Trial Using Mindful Sport Performance Enhancement (MSPE). Journal of Clinical Sport Psychology, 25, 357-376. https://doi.org/10.1123/jcsp.3.4.357

Gardner, F. L., \& Moore, Z. E. (2004). A Mindfulness-Acceptance-Commitment-Based Approach to Athletic Performance Enhancement: Theoretical Considerations. Behavior Therapy, 35, 707-723. https://doi.org/10.1016/S0005-7894(04)80016-9

Gardner, F. L., \& Moore, Z. E. (2007). The Psychology of Enhancing Human Performance: The Mindfulness-Acceptance-Commitment (MAC) Approach. New York: Springer Publishing.

Geschwind, N., Peeters, F., Drukker, M., van Os, J., \& Wichers, M. (2011). Mindfulness Training Increases Momentary Positive Emotions and Reward Experience in Adults Vulnerable to Depression: A Randomized Controlled Trial. Journal of Consulting and Clinical Psychology, 79, 618-628. https://doi.org/10.1037/a0024595

Girden, E. R. (1992). ANOVA: Repeated Measures. Newbury Park, CA: Sage. https://doi.org/10.4135/9781412983419

Goyal, M., Singh, S., Sibinga, E. M., Gould, N. F., Rowland-Seymour, A., Sharma, R., Shihab, H. M. et al. (2014). Meditation Programs for Psychological Stress and Well-Being: A Systematic Review and Meta-Analysis. JAMA Internal Medicine, 174, 357-368. https://doi.org/10.1001/jamainternmed.2013.13018

Gross, J. J., \& John, O. P. (2003). Individual Differences in Two Emotion Regulation Processes: Implications for Affect, Relationships, and Well-Being. Journal of Personality and Social Psychology, 85, 348-362. https://doi.org/10.1037/0022-3514.85.2.348

Hardy, L., Jones, J. G., \& Gould, D. (1996). Understanding Psychological Preparation for Sport: Theory and Practice of Elite Performers. New York: Wiley.

Hasker, S. M. (2010). Evaluation of the Mindfulness-Acceptance-Commitment (MAC) Approach for Enhancing Athletic Performance. Doctoral Dissertation, Indiana, PA: Indiana University of Pennsylvania. http://dspace.iup.edu/handle/2069/276

Hodgins, H. S., \& Adair, K. C. (2010). Attentional Processes and Meditation. Consciousness and Cognition, 19, 872-878. https://doi.org/10.1016/j.concog.2010.04.002

Hofmann, S. G., Sawyer, A. T., Witt, A. A., \& Oh, D. (2010). The Effect of Mindful-NessBased Therapy on Anxiety and Depression: A Meta-Analytic Review. Journal of Consulting and Clinical Psychology, 78, 169-183. https://doi.org/10.1037/a0018555

Ivarsson, A., Johnson, U., Andersen, M. B., Fallby, J., \& Altemyr, M. (2015). It Pays to Pay Attention: A Mindfulness-Based Program for Injury Prevention with Soccer Players. Journal of Applied Sport Psychology, 27, 319-334. https://doi.org/10.1080/10413200.2015.1008072

Jackson, P., \& Delehanty, H. (1996). Sacred Hoops: Spiritual Lessons of a Hardwood Warrior. New York: Hyperion.

Jackson, S. A., \& Csikszentmihalyi, M. (1999). Flow in Sports. Champaign, IL: Human Kinetics.

Jain, S., Shapiro, S. L., Swanick, S., Roesch, S. C., Mills, P. J., Bell, I., \& Schwartz, G. E. (2007). A Randomized Controlled Trial of Mindfulness Meditation versus Relaxation Training: Effects on Distress, Positive States of Mind, Rumination, and Distraction. 
Annals of Behavioral Medicine, 33, 11-21. https://doi.org/10.1207/s15324796abm3301_2

Jensen, C. G., Vangkilde, S., Frokjaer, V., \& Hasselbalch, S. G. (2012). Mindfulness Training Affects Attention-Or Is It Attentional Effort? Journal of Experimental Psychology: General, 141, 106-123. https://doi.org/10.1037/a0024931

Kabat-Zinn, J. (1994). Wherever You Go, There You Are: Mindfulness Meditation in Everyday Life. New York: Hyperion.

Kaufman, K. A., Glass, C. R., \& Arnkoff, D. B. (2009). Evaluation of Mindful Sport Performance Enhancement (MSPE): A New Approach to Promote Flow in Athletes. Journal of Clinical Sport Psychology, 25, 334-356. https://doi.org/10.1123/jcsp.3.4.334

Keng, S.-L., Smoski, M. J., \& Robins, C. J. (2011). Effects of Mindfulness on Psy-Chological Health: A Review of Empirical Studies. Clinical Psychology Review, 31, 1041-1056. https://doi.org/10.1016/j.cpr.2011.04.006

Lutkenhouse, J. M. (2007). The Case of Jenny: A Freshman Collegiate Athlete Experiencing Performance Dysfunction. Journal of Clinical Sport Psychology, 1, 166-180. https://doi.org/10.1123/jcsp.1.2.166

Michalak, J., Heidenreich, T., Ströhle, G., \& Nachtigall, C. (2008). Die deutsche Version der mindfulattentionandawarenessscale (maas): Psychometrische Befunde zu einem Achtsamkeitsfragebogen. Zeitschrift für Klinische Psychologie und Psychotherapie, 37, 200-208. https://doi.org/10.1026/1616-3443.37.3.200

Moore, A., \& Malinowski, P. (2009). Meditation, Mindfulness and Cognitive Flexibility. Consciousness and Cognition, 18, 176-186.

https://doi.org/10.1016/j.concog.2008.12.008

Moran, A. L. (1996). The Psychology of Concentration in Sport Performance: A Cognitive Approach. Hove: Psychology Press.

Ortner, C. N., Kilner, S. J., \& Zelazo, P. D. (2007). Mindfulness Meditation and Reduced Emotional Interference on a Cognitive Task. Motivation and Emotion, 31, 271-283. https://doi.org/10.1007/s11031-007-9076-7

Pineau, T. R. (2013). Effects of Mindful Sport Performance Enhancement (MSPE) on Running Performance and Body Image: Does Self-Compassion Make a Difference. Unpublished Doctoral Dissertation, Washington DC: The Catholic University of America.

Pineau, T. R., Glass, C. R., Kaufman, K. A., \& Bernal, D. R. (2014). Self-and Team-Efficacy Beliefs of Rowers and Their Relation to Mindfulness and Flow. Journal of Clinical Sport Psychology, 8, 142-158. https://doi.org/10.1123/jcsp.2014-0019

Robazza, C., Pellizzari, M., \& Hanin, Y. (2004). Emotion Self-Regulation and Athletic Performance: An Application of the IZOF Model. Psychology of Sport and Exercise, 5, 379-404. https://doi.org/10.1016/S1469-0292(03)00034-7

Robins, C. J., Keng, S. L., Ekblad, A. G., \& Brantley, J. G. (2012). Effects of Mind-FulnessBased Stress Reduction on Emotional Experience and Expression: A Randomized Controlled Trial. Journal of Clinical Psychology, 68, 117-131. https://doi.org/10.1002/jclp.20857

Schwanhausser, L. (2009). Application of the Mindfulness-Acceptance Commitment (MAC) Protocol with an Adolescent Springboard Diver: The Case of Steve. Journal of Clinical Sport Psychology, 3, 377-395. https://doi.org/10.1123/jcsp.3.4.377

Tang, Y.-Y., Ma, Y., Wang, J., Fan, Y., Feng, S., Lu, Q., Fan, M. et al. (2007). Short-Term Meditation Training Improves Attention and Self-Regulation. Proceedings of the National Academy of Sciences of the United States of America, 104, 17152-17156. https://doi.org/10.1073/pnas.0707678104 
Thompson, R. W., Kaufman, K. A., De Petrillo, L. A., Glass, C. R., \& Arnkoff, D. B. (2011). One Year Follow-Up of Mindful Sport Performance Enhancement (MSPE) with Archers, Golfers, and Runners. Journal of Clinical Sport Psychology, 5, 99-116. https://doi.org/10.1123/jcsp.5.2.99

Valentine, E. R., \& Sweet, P. L. (1999). Meditation and Attention: A Comparison of the Effects of Concentrative and Mindfulness Meditation on Sustained Attention. Mental Health, Religion \& Culture, 2, 59-70. https://doi.org/10.1080/13674679908406332

Van den Hurk, P. A., Giommi, F., Gielen, S. C., Speckens, A. E., \& Barendregt, H. P. (2010). Greater Efficiency in Attentional Processing Related to Mindfulness Meditation. The Quarterly Journal of Experimental Psychology, 63, 1168-1180. https://doi.org/10.1080/17470210903249365

Weinberg, R. S., \& Gould, D. (2014). Foundation of Sport and Exercise Psychology. Champaign, IL: Human Kinetics.

Wolanin, A. T. (2004). Mindfulness-Acceptance-Commitment (MAC) Based Performance Enhancement for Division I Collegiate Athletes: A Preliminary Investigation. Philadelphia, PA: La Salle University.

Zeidan, F., Johnson, S. K., Gordon, N. S., \& Goolkasian, P. (2010). Effects of Brief and Sham Mindfulness Meditation on Mood and Cardiovascular Variables. The Journal of Alternative and Complementary Medicine, 16, 867-873.

https://doi.org/10.1089/acm.2009.0321 


\section{Appendix}

\section{Mindful Attention Awareness Scale (MAAS)}

Day-to-Day Experiences Instructions: Below is a collection of statements about your everyday experience. Using the 1 - 6 scale below, please indicate how frequently or infrequently you currently have each experience. Please answer according to what really reflects your experience rather than what you think your experience should be. Please treat each item separately from every other item.

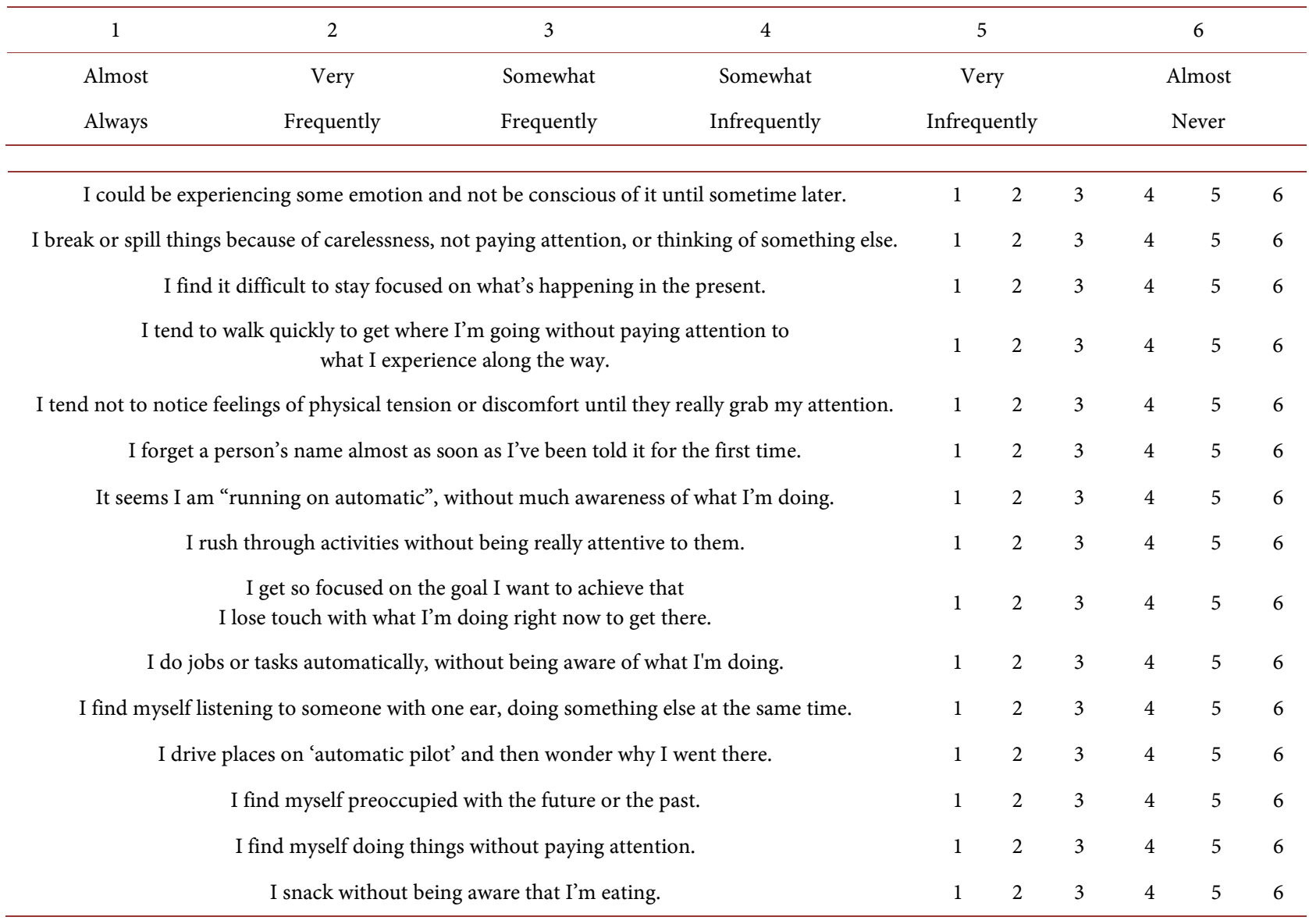


Submit or recommend next manuscript to SCIRP and we will provide best service for you:

Accepting pre-submission inquiries through Email, Facebook, LinkedIn, Twitter, etc. A wide selection of journals (inclusive of 9 subjects, more than 200 journals)

Providing 24-hour high-quality service

User-friendly online submission system

Fair and swift peer-review system

Efficient typesetting and proofreading procedure

Display of the result of downloads and visits, as well as the number of cited articles Maximum dissemination of your research work

Submit your manuscript at: http://papersubmission.scirp.org/

Or contact psych@scirp.org 